\title{
Research in Children's Information Seeking Behavior
}

Mansor, Yushiana

International Association of School Librarianship. Selected Papers from the ... Annual Conference; 2002;

Education Database pg. 99

\section{Research in Children's Information Seeking Behavior}

\author{
Yushiana Mansor, Ph.D \\ Dept. of Library \& Information Science \\ Kulliyyah of Information and Communications Technology \\ International Islamic University Malaysia, \\ Jalan. Gombak \\ 53100 Kuala Lumpur \\ Malaysia \\ yushiana@iiu.edu.my
}

\begin{abstract}
Provides an overview on the significance of studying information seeking behavior of children to enhance the role of school libraries. The literature on children's information seeking behavior is reviewed and integrated into the perspective of school library services. Discussion on the differert models of information seeking is presented. Focuses on children's information seeking behavior in the electronic environment. Outlines issues related to children's access and barriers to information. An analysis of research methodology used is provided. Offers suggestions on the future research direction with emphasis on the Malaysian school libraries environment.
\end{abstract}

\section{Introduction}

Research on information seeking behavior is aimed at understanding why and how people use information. The concept of information-seeking behavior, according to Krikelas (1983) is an active process which begins when someone perceives that the current state of knowledge is less than what is needed. Marchionini (1992) describes it as a process in which humans purposefully engaged in order to change their state of knowledge. It is a process of acquiring knowledge. According to Wilson (2000, p.49), information seeking behavior is "the purposive seeking for information as a consequence of a need to satisfy some goal."

A significant body of literature can be found in this area which mainly focuses on the information seeking behavior of adults. Very little is known about the information seeking behavior of children and the techniques that could be used to determine the different aspects of their information behavior in a particular setting. The role of sshool libraries and other information institutions serving the children population could only be further enhanced if all the services and products offered are designed to meet the information seeking behavior of children. One of the key prerequisites to this is to understand the information seeking behavior of children. This paper attempts to bring together the required information towards a better understanding of the children's information needs and uses by studying the channels of information used, barriers to information, impacts of technology, and the role of information institutions. Finally, this paper provides an overview of the different methods that can be used to study children's information seeking behavior and its related phenomena. Such information would be very useful in the effort towards effectively serving the children population by offering information products and services that are tailored for them. 


\section{School Libraries and Children}

The development of research activities in the area of human information seeking behavior can be traced back to as early as the 1920's in the U.S. when libraries had already been acknowledged as playing important role in charge of information provision for the community. Earlier studies were conducted mainly to evaluate how effective were the services offered in relation to the users they served. However, it was only after the mid-1970s that most of the research work on information behavior started focusing on the user instead on the services.

The emphasis on user-centered information services have called for more research done in the library and information science field with the goal of better understanding the information seeking behavior of end users. This paradigm shift has also contributed to a significant progress in the research methods used. Thus is evidenced through the shift from the use of quantitative to qualitative research method.

As research in information seeking behavior suggests that there are individual differences in how people seek information, many studies have been done to further investigate how specific groups of library users seek information. Very prominent in the research groups are library users in the academic world such as humanists, scientists, engineers, historians, etc. There has also been a positive trend towards studying the information seeking behavior of users outside the academic world such as the poor, elderly, women, and children. The children population represents one type of information users who are undoubtedly very closely attached to school libraries. As the world of children is partly revolved around their schooling activities, there is no doubt that the school environment plays a major role as an information channel for children.

School libraries, in particular, are important institutions in charge of providing information products and services to school children. In most parts of the world today, including Malaysia, the role of school libraries is becoming more important in preparing the younger generation to face the challenges of knowledge-based society and globalization. School libraries are no longer just fully stacked with books and other printed media, but also electronic information sources. But, are all these enough and useful for the children? Are we serving them with what they want? Who can best give us the answer if not the children themselves. A marketing approach to library services put users at the focal point. The basic rule is, 'know thy users!'. One way of knowing them, is of course by studying their information seeking behavior.

\section{Models of Information Seeking}

Different models have been developed over the years to represent human information seeking behavior. Although most of the models were based on studies done on adult population, they have also been adopted as a basis to study information seeking behavior of children. Interestingly, the development of information seeking models have demonstrated a trend towards a shift from system-oriented to user-oriented approach. Among important models are Belkin's Anomalous State of Knowledge (ASK) (Belkin, 1980), Dervin's SenseMaking Approach (Dervin, 1989), and Kuhlthau's Information Search Process (ISP) (Kuhlthau, 1989). 
How are these models relevant to children? Conceptumlly, all the models acknowledge that a person must experience a state of 'information need" as a precondition before engaging in an information seeking activity. For example. Dervin's Sense-Making Approach looked at the conceptual and theoretical premises and set of related methodologies for assessing how people make sense of their world and how they use information and other resources in the process. This model suggests that people engaged them selves in information seeking activities when they experienced a sense of discontinuity or gap in the current knowledge about something. Thus, the precursor to information seeking, as suggested by this model and other models, is 'information needs'.

Interestingly, what are the 'information needs' of children? Do children have information needs? And if so, how are their information needs different from other users? In most of the studies conducted, children were engaged in information seeking activities to fulfill class requirements. Realistically, the life of children is not limited within the boundary of school environment. With their very inquisitive minds, children are a!so active information seekers outside the school environment. There is a lack of research done on children's everyday decision making process and how they fulfill their information gap. As the decision to seek or not to seek information is affected by many factors, the literature does not lead to any concrete evidence as to what are other contributing factors beside clossroom assignments that lead children to seek information. Thus, not much is known on how children fulfill their everyday information needs.

Gross (1999) tested the theoretical model of school children's nformation-seeking behavior called 'imposed query'. Possible imposers in the school environment are teachers, parents, children, and school librarians. Based on previous models proposed by Dervin, and Belkin, Gross proposed a model that describes how children generate queries and how they are presented to an information intermediary (Figure 1).

Figure 1.

The Imposed Query Model (Gross, 1995)

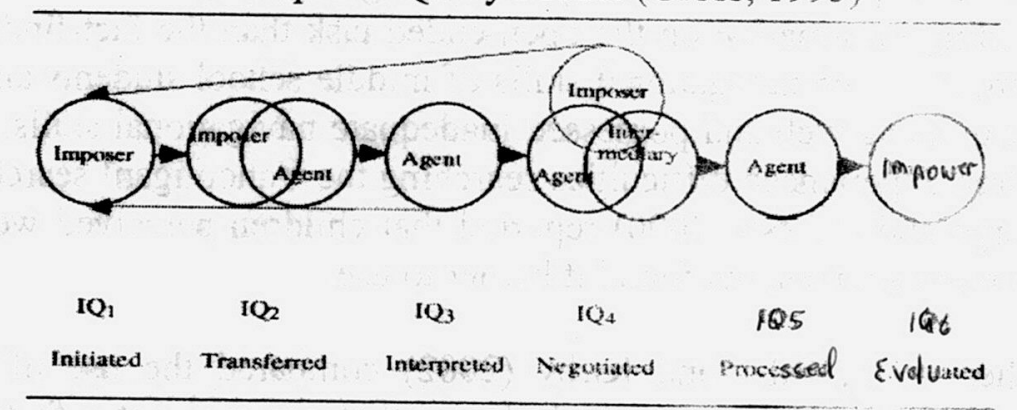

The model suggests that a child's query moves along different ctages and the process may be affected by feeling, beliefs, or both. In addition, this model takes into account the role of 'imposers' in the process. For example, the way a student feels abont a teacher influences the way the student seeks appropriate answers, and recognizes required answers. The model also recognizes what is called 'double imposed queries' wherc students impose on parents to do the information seeking for them in the library. In such cases, school children's information seeking can thus be regarded as a shared information secking phenomenom.

This model supports the general notion in information seeking studies that users exhibit common characteristics of information behaviors at different stages of information seeking process. Worth noting, children's feeling and beliefs towards certain individuals affect their 
information seeking behavior. It can be deduced that human intermediaries such as school librarians or media center managers must possess personalities that would encourage and promote a successful information seeking process. System intermediaries such as online or card cataloging systems, in-house or CD-ROM databases must be designed in a manner that is easily approachable by students.

\section{Electronic Environment}

The role of computers in schools cannot be disputed. It is a common scene today that school libraries are equipped with computers, supporting services such as the Intenet, OPAC, and variety of databases. Hough and Ellis (1997) reported on the "Cyber Space learning for kids' (CLUK) project for children aged 5-16 across Europe with the objective of providing online services such as databases of information and teaching and learning resources. Teachers surveyed expressed that such service would promote children learning by children themselves becoming the researchers and explorers of information. Computers have the potential to provide children with access to vast amounts of information that helps them develop research skills and become independent learners. With the immense potential of electronic sources to provide information, a lot of studies have been conducted that looked at how children seek information in the electronic environment.

The World Wide Web is becoming part and parcel of today's information environment. With its multimedia, hypertext-linking characteristics, the Web is a very attractive information channel for children. Research on children's use of the Web, however, indicated that this user group has cognitive difficulties constructing effective search strategies, and most of them do not use the Web effectively.

Schacter et al. (1998) studied elementary school children's searching behavior in using the Web for fact finding and research tasks. The study found children as interactive information seekers, preferring to browse rather that plan systematic and analytic search strategies. Children experienced difficulty in finding relevant information, and were more successful in finding information on the open-ended task than the fact-finding task. Large et al. (1999) investigated web navigational skills of middle school students and found that they were inefficient in using web and possessed inadequate navigational skills. Bilal (2000) also found that children experienced difficulties searching the Yahooligan! search engine designed for children. Large and Behesti (2000) reported that children perceived web accessibility as an advantage to point sources, but found it harder to use.

In another study, Bilal and Kirby (2002) compared the use of Yahooligans! by children and graduate students. The study found that age was not a factor that influenced children's information seeking behavior on the web, but it was the ability to recover from break downs, navigational style, and focus on task.

Findings of these studies suggested the importance of training children on web navigational skills. They also need to be equipped with basic research skills, particularly in how to express their information needs and translate their queries in the manner that is acceptable by the different search engines. Children need to adapt themselves to the use of the web and search engines in order to learn new techniques that would support effective web navigation. 
The use of online public access catalog (OPAC) by children is also another popular research area. The OPAC is an instrumental intermediary between the students and the library collection. In the early type of OPAC, Edmond, Moore, and Beacom (1990) found 10\% success among children who used OPACs with a touch-screen on-line interface. Solomon (1993) in his study found 66\% success on standard OPACs. In the Science Library Catalog Project, Borgman et al. (1995) and Hirsh (1997), revealed $80 \%$ rate of success of OPAC used by children.

Solomon's study focused on the search moves of children grades 4-6 in using OPAC (Solomon, 1993). The study looked at 5 areas: overall success of children using the OPAC and the reasons for their success or break down; strategies that children used to control the OPAC; interface, and correspondence between children's search terms and the subjects headings used in the database. There was observed change overtime in children's information search using the OPAC. Different search moves were observed being made by students. Children who employed complex search moves were less successful in locating information than children who employed simple moves with concrete concepts. Their failure was mainly due to the use of terminology that did not match the controlled vocabulary used in the OPAC. The following user requirements of OPAC use were proposed: ability to monitor system response; knowledge of appropriate follow-up actions; content knowledge in areas of search; knowledge of formal requirements (punctuation, space); knowledge of requirements for wellformed queries; ability to evaluate focus (subject, title, author, or combination); understanding of intended uses and products of the OPAC; ability to read words in line with interests, and; ability to locate keys on keyboard, spell, and review term entry.

Domain knowledge, or subject knowledge has also been found as a contributing factor to children success in using the OPAC. The Science Library Catalog (SLC) study looked at the effect of domain knowledge on children's success in OPAC use (Borgman et al., 1995). The SLC used the Dewey Decimal-based hierarchical browsing and revealed that children have very little difficulty navigating the hierarchical structure of SLC. However, differences in success rates among children were found to be influenced by domain knowledge, spelling, and vocabulary problems. Hirsh (1997) conducted another study using the SLC, examining the effects of task complexity and domain knowledge in children's success in using the catalog. The children were assigned two tasks: single-browsing tasks and complex browsing tasks. It was also found that, children's domain knowledge has a significant effect on their success regardless of the complexity of the search task.

Children's system knowledge on the type of task assigned also plays a major role in determining successful use of electronic information sources. Marchionini (1989) conducted a study that assigned children two tasks, fact finding and research, using the Grolier's Electronic Encyclopedia on CD-ROM. Despite only being given minimal prior training, children in this study were able to use the full-text database. However, they had difficulty in formulating effective search strategies and were more successful in the open task than in the closed task. Three factors were found to be influencing children's searching behavior and success: the structure of the tasks, cognitive abilities, and level of conceptual understanding of how to use a multimedia encyclopedia.

Large, et al. (1998) studied children's interaction with three types of interfaces using a multimedia encyclopedia. Despite the differences in interfaces, children were able to manipulate the interfaces, but experienced difficulties in constructing effective queries. Large (1993) compared the use of print encyclopedia and its CD-ROM equivalent by 
elementary school childmen. Fifty percent $(50 \%)$ of the children were able to find texts for complex queries in both sources. As it was not evidenced that retrieval time was shorter in using CD-ROM than its print equivalent; this study revealed that children's information seeking is more siguitis antly influenced by the types of search task (simple vs. complex) than the type of the source used (print vs. CD-ROM).

There were $2 / 50$ studies that looked at gender issue in children information seeking behavior. Large et al (2002) studied how grade 6 boys and girls working in same sex groups retrieve information from the web. It was observed that boys used fewer words when formulating queries, spent less time viewing progress and clicked more hypertext links per minute than girls. Boys also performed more page jumps per minute than girls and were much more interactively engaged with the web in terms of the frequency of mouse clicks. Thus, the study suggests that the group of boys is more active on the web than girls.

Findings of these studies suggest the attractiveness of electronic information sources to children. The role of school libraries in educating students to use these services must be enhanced. Galpin and Schilling (1988) suggested that children need to employ a variety of information skills when using electronic databases, such as collecting and selecting information, sorting and ordering information, applying logical operator, validating information, looking for relationships, and forming and testing hypothesis.

Fasick's study relating to children's use of electronic media concluded that improved hardware design, better communication training for users, and the use of gender-neutral software may all contribute to more effective use of online catalogs, electronic databases, and other computer-aided learning tools by children (Fasick, 1992). Every child must have an equal opportunity to use technology-based information media, more effective hardware and software must be developed, equality of access to computers must be ensured, and more software that meets the educational goals of all students must be developed.

On the information searching skills of students, most findings confirmed that children are active searchers. Their search performance is mainly affected by lack of systematic planning and poor analytic search strategies. Children need to be educated on how to better plan their searches, conceptualize solution paths, and how to organize, structure, manage, and represent information they find. Further research could investigate how web interfaces and research engines can be developed to target a specific gender, how teachers can help children plan and revise their search strategies, and how cooperative work between classmates can be facilitated.

\section{Barriers to Information}

This section will look at the various factors that could affect children's access to information. Access dccording to Buckland (1991), is the means that enable an information seeker or an inquirer to learn or to become informed. To ensure access of information to children, among the barriers that must be tackled are: identification of information sources, cognitive access (understanding), and acceptability.

Students in the study conducted by Large et al. (1998) demonstrated the ability to selectively extract information and to evaluate sources in terms of usefulness as well as enjoyment and ease of use Schacter et al. (1998) looked at elementary school children's use 
of the Internet and found that most children believed that the information found on the Internet was true.

The literature has also identified a few important factors that could become barriers to children information seeking process. One factor is the conflict of paradigms. The Information Search Process (ISP) model proposed by Kuhlthau (1989) is famous for its cognitive approach. This model states that information search process involves the whole experience of the person, including feelings, thoughts and actions. In her study, Kuhlthau observed that most of the failures in library research resulted from the mismatch between the library paradigm and the user paradigm. The bibliographic paradigm of the library is based on certainty and order, while the users' is of uncertainty and confusion. As a result, there is gap between patterns of information provision and users' natural process of information use.

The same conflict can also be found in school libraries serving the children's population. Moore and George (1991) found that students did not have enough information on the function of the card catalogs. The study suggested that the information printed on the card catalogs did not help much in their information seeking process. In addition, they did not have enough knowledge of the relationship between catalog cards, books, and the shelving system. Students also did not have knowledge of the Dewey Decimal Classification (DDC) system used by the library.

The same study also found that children's poor understanding of subject index had resulted in the formulation of general and frequently vague questions. Although they can refer to the use of subject index, this however requires them to both reduce and increase the scope of topic in order to select the most appropriate search term. Thus, students are not only required to have subject knowledge but also knowledge of the various ways in which topics can be recognize and represented in classification systems.

How do children select books? Moore and George (1991) found that the table of contents and indexes were not useful enough in assisting children in the selection process. Most books did not have a proper lay out of the table of contents, and the quality of indexes was not good. As a result, students failed to select relevant keywords that matched with the indexes.

Findings of previous studies also suggest that both domain knowledge and system knowledge factors could significantly influence children's information search process in the electronic environment. Domain knowledge or subject background helps children to conceptualize their information needs. Borgman et al. (1995) and Hirsh (1997), for example, in the SLC study had clearly identified the role of domain knowledge in children's information seeking. When interacting with any information retrieval system, users would need to translate their information needs into the terms that are acceptable by the system. Solomon's study found that children's failure in using OPAC was mainly due to children's use of terminology that did not match the controlled vocabulary used in the OPAC (Solomon, 1993).

Most research findings agreed that children lack the skill on how to formulate search strategies, and do not have a conceptual understanding of the system used. Bilal (2001) observed that children had difficulty with open task or research-based activity compared to fact-finding activity. This signaled a need to provide children with basic research skills. Designers of information retrieval systems for children must take into consideration the 
cognitive levels of children and provide the necessary mechanisms that would help children in the search formulation and retrieval process. As children normally do not know of alternative strategies when they encountered barriers during different stages of their information seekin 8 process, they must be equipped with the necessary navigational skills that would allow them to recover from search break downs (Bilal and Kirby, 2002).

\section{Methodology}

How do we study children's information seeking behavior? Research applies some set of theoretical and empirical tools to try to increase our understanding of some set of phenomena or events. The main ingredients in research are that they must have some content that is of interest, some ideas that give meaning to that content, and some techniques or procedures by means of which those ideas and contents can be studied. Among the research methods that can be applied are experiments (lab or field), surveys, observations, interviews, focus groups, bibliometrics (content \& citation analysis), transaction log analysis, content or discourse analysis. All methods are valuable, but they also have weaknesses or limitations. This suggests that although the different methods enable fact findings, they also limit evidence. To offset the weaknesses of a particular instrument, multiple methods is a common approach in studying children's information seeking behavior.

In studying children's information seeking behavior, it is common for researchers to adopt the multiple methods approach. A general observation is that qualitative research was found to be more suitable in studying children's information seeking behavior. The nonmanipulative or non-controlling characteristics of qualitative research help researchers to understand children from their own point of view. This method allows us to examine the dynamics of a process rather than static attributes of a process.

Large (2002) studied how grade 6 boys and girls working in same sex groups retrieve information from the web using a case study approach that recorded on video tape multiple sessions of information recording from the web. A questionnaire was also used to gather demographics data of children.

Paul Solomon, media educator of 1989 for the state of Virginia, was one of the first researchers in the schuol library media field to use qualitative method (Solomon, 1993). His study of children's use of the OPAC employed a naturalistic approach that applies data collection methods in situation that are as 'actual' as possible. Methods used were observation of children using the OPAC; interviews with children, teachers, the reading specialist, the library media specialist, and volunteers; think-aloud protocols; and documentary evidence. The different methods allowed the researcher to explore and discover patterns of behavior that lead to children's successes and failures in the use of OPAC.

Bilal (2000), investigated the success and information seeking behavior of seventhgrade students using the Yahooligans! Search engine. This study looked at the cognitive, physical, and affective perspectives of children. Children's behavior was captured using Lotus ScreenCam, their affective states were elicited through exit interviews, while a questionnaire was designed to gather their prior experience in using Yahooligans! and the
web.

Carey, McKechnie, and McKenzie (2001) shared the methodology that would help researchers gain access to the children's population. Their study suggests that it is important 
for researchers to gain access to the inside world of children in order to understand them better. Gaining access requires them to share certain 'insider' characteristics. They also suggest that researchers have to take both the roles of insider and outsider of children's information world. However, they cautioned that the following factors must be considered when doing a naturalistic study; respect for participants; respect for sensitivity to participants surroundings, flexibility, time for developing trust, recognition of trust, maintaining trust, role playing, and reciprocity.

Depending on the age of the children, the use of interviews and questionnaires are not recommended for children whose oral and language skills are not well developed. This is among the methodological challenges presented by young school children as subjects in library and information science research. McKechnie suggested the use of ethnographic observation techniques using three methods, that is audio-reading of children's naturally occurring talk, participant observation, and diary keeping by key informants. The drawback of observer effect could be lessen by enhancing subject familiarity with the researcher and equipment, maintaining clear communication, and staying out of direct sight lines.

Moore and George (1991) explored the cognitive difficulties encountered by grade 6 children in New Zealand by using intensive think-aloud sessions. They also conducted retrospective interviews which were recorded on video and audiotapes and further analyzed these with respect to the nature of the library system, books, and children's perception of them.

Large et al. (1998) adopted different methodology where experimental rather than a field environment was chosen to collect qualitative data under controlled conditions. To study the impact user competence on information retrieval design, three identical workstations were installed in the classroom, each with different CD-ROM multimedia titles. Samples of search transactions were captured on videotape and a microphone was also installed to capture both screen images and voices synchronously. Subjects' assignments were marked and their oral presentations were audio-taped. A questionnaire consisting of close and open-ended questions were administered to seek subjects' opinions of the three multimedia sources used.

Borgman et al. (1995) used online monitoring as a technique for evaluating children's use of OPAC. Online monitoring, or transaction log analysis, are computer-based methods of capturing user behavior. This technique could provide useful information for describing patterns of system usage, analyzing frequency, type, and context of actions and errors and recording the amounts of time spent in various stages of a task. However, this technique could only provide extensive detail on what the researcher is doing but no data on why the researcher is doing it. Thus, this technique is normally combined with other techniques of obtrusive evaluation method such as interviews, verbal protocols, direct observation, or playing back the research.

\section{Conclusions}

Based on the above discussion, some important lessons can be learned and their implications on research, school library services, and system design are outlined as below:

\section{Research}

- There is still a lack of research in the area of children's information seeking behavior in school libraries. Not much is known about children's perception of school library 
services, their preferred sources of information, why they engage in information seeking process, etc.

- As most of the previous research was conducted in developed countries, very little is known about the information seeking behavior of children from developing, or less developed countries. In an effort to bridge the digital divide, such studies are urgently needed to better prepare and equip the younger generation with appropriate information skills.

- More research should be encouraged based on the real information needs of children. Not much is known pertaining to children's everyday life information seeking activities and how school libraries can serve them.

- Careful consideration must be given to the methods used to study information seeking behavior of children.

- The focus on electronic information sources has overshadowed children's use of other types of library products and services.

- Cross-cultural studies are needed to investigate the effect of cultural and language background on children's information seeking behavior.

- More studies are needed that focus on special groups of children, such as children with disabilities.

\section{School library services}

- The products and services provided by school libraries must be tailored towards the information needs, and information seeking behavior of children.

- Lessening the effect of the 'bibliographic paradigm' in libraries would promote a more successful information seeking process by children.

- Information skills development of children must be emphasized. This includes helping children in defining their information needs, determining the required information, searching information, retrieving information, evaluating information, and presenting information.

\section{Malaysian perspective}

- Children's information seeking behavior is still an unexplored area in the Malaysian school library context. The emergence of smart schools and the Malaysian government's vision of building a knowledge-based society would definitely enhance the role of school libraries in Malaysia. Understanding the information seeking behavior of children is deemed necessary to ensure that the products and services offered are useful for them. 


\section{References}

Belkin, N. J. (1980). Anomalous state of knowledge as a basis for information retrieval. The Canadian Journal of Information Science 5, 136-139

Bilal, D (2000). Children's use of the Yahooligans! Web search engine: I. Cognitive, physical, and affective behavior on fact-based search tasks. Journal of the American Society for Information Science and Technology, 51(7), 646-665.

Bilal, D (2001). Children's use of the Yahooligans! Web search engine: II. Cognitive and physical behaviors on research tasks. Journal of the American Society for Information Science and Technology, 52(2), 118-136.

Bilal. D. \& Kirby, J. (2002). Differences and similarities in information seeking: children and adults as Web users. Information Processing and Management, 38(5), 649-670.

Borgman, C. et al. (1995). Children's search behavior on browsing and keyword online catalogs: the Science Library Catalog project. JASIS, 46, 663-684.

Borgman, C. et al. (1996). Rethinking online monitoring methods for information retrieval systems: from search product to search process. Journal of the American Society for Information Science, 47(7), 568-583.

Buckland, M. (1991). Information and information systems. NY: Praeger.

Carey, R. F. et al. (2001). Gaining access to everyday life information seeking. Library \& Information Science Research, 22(4), 319-334.

Dervin, B. (1989). From the mind's eyes of the "users": the sense-making approach. In R. Rice \& C. Atkins (Eds.), Public communication campaigns (pp. 67-86). Newbury Park, CA: Sage Publications.

Edmonds, L. et al. (1990). The effectiveness of an online catalogs. School Library Journal, 36 (October), 28-32.

Fasick, A. M. (1992). What research tells us about children's use of information media. CLJ, February, 51-54.

Galpin, B., \& Schilling, M. (1988). Computers, topic work, and young children: Learning to use information in the primary classroom. UK: The British Library.

Gross, M. (1999). Imposed queries in the school library media center: a descriptive study. Library \& Information Science Research, 21(4), 501-521.

Hirsh, S. G. (1997). How do children find information on different types of tasks? Children's use of the Science Library Catalog. Library Trends, 45, 725-745.

Hough, J. \& Ellis, D. (1997). Acquiring skills for tomorrow today: "Cyberspace learning for kids". Education + Training, 39(7), 249-255. 
Krikelas, J. (1983). Information-seeking behavior: patterns and concepts. Drexel Library Quarterly; 19 (2) 83, 5-20.

Kuhlthau, C.C. (1989). Information Search Process: A summary of research and implications for school library media programs. School Library Media Quarterly, 18. 19-25.

Large A. \& Bahesti, L (2000). The Web as a classroom resource: reactions from the users. Journal of the American Society for Information Science, 51(12), 1069-1080.

Large, A., et al. (1998). Information seeking in a multimedia environment by primary school students. Library \& Information Science Research, 20(4), 343-376.

Large, A. et al. (1999). Information seeking on the Web: navigational skills of grade-six primary school students. In: Proceeding of the 62nd ASIS annual meeting, October 31-November 4, 1999, Washington, (1999), pp. 84-97.

Large, A., et al. (2002). Gender differences in collaborative web searching behavior: An elementary school study. Information Processing and Management, 38(3), 427-443.

Marchionini, G. (1989). Information seeking Strategies of novices using a full-text electronic encyclopedia. JASIS, 40, 54-66.

Marchionini, G. (1992). Interfaces for end-user information seeking. JASIS, 43, 156-163.

Moore, P. A., \& George, A. S. (1991). Children as information seekers: The cognitive demands of books and library systems. School Library Media Quarterly, spring, 161168.

Schacter, J. et al. (1998). Children's internet searching on complex problems: performance and process analyses. Journal of the American Society for Information Science, 49(7).

Solomon, P. (1993). Children's information retrieval behavior: A case analysis of an OPAC. Journal of the American Society for Information Science, 44(5), 245-264.

Wilson $_{2}$ T. D. (2000). Human information behavior. Information Science Research 32 (2000), pp. 49-56. 